\title{
Intelligence Context Aware Mobile Navigation using Augmented Reality Technology
}

\author{
Ahmad Hoirul Basori ${ }^{1)^{*}}$, Abdullah M. Al-Ghalib Al-Sharif ${ }^{2)}$, Atiah O. Faraj AL-Oufi ${ }^{3)}$, Alaa Omran \\ Almagrabi ${ }^{4}$, Omar M. Barukab ${ }^{5}$ \\ ${ }^{144) 5)}$ Faculty of Computing and Information Technology Rabigh, King Abdulaziz University \\ Jeddah, Kingdom of Saudi Arabia \\ 1)abasori@kau.edu.sa \\ 4)aalmagrabi3@kau.edu.sa \\ ${ }^{5)}$ obarukab@kau.edu.sa \\ ${ }^{2) 3)}$ Global Cyber Security Centre, Sabic \\ Jubail, Kingdom of Saudi Arabia \\ ${ }^{2)} \mathrm{A}-10 @$ outlook.com \\ 3)a.teh11aofe@hotmail.com
}

Article history:

Received 2 April 2018

Revised 16 April 2018

Accepted 18 April 2018

Available online 28 April 2018

Keywords:

Augmented reality

Context aware

Intelligence

Outdoor location

\section{Abstract}

Most of the technologies of today's world, which are enriched with various powerful features and amazing quality characteristics, enables software developers to come up with best possible software solutions, no matter what the context of the particular issue. Technologies such as Augmented Reality (AR), is utilized almost every kind of fields in today's society. As computers become more advanced through mobile devices and wearable technology, augmented reality will become a seamless experience that is a part of our everyday lives. In the context of this work, an Intelligence mobile navigation application for the King Abdul Aziz University Rabigh is developed enabling the user to find specific locations on campus and offers the ability to explore the campus environment via AR. Furthermore, the system, Mobile Campus Navigation with Augmented Reality application is capable of giving guidance in outdoor location navigating and retrieving details of campus officials and lecturers. With the proposed system, it is expected to serve as a useful and informative navigate helper for both students of King Abdul Aziz University and for the visitors, at outdoor locations and to use as an application to check officials and lecturer availability and retrieve detail about them when they are not available at the office at any time.

\section{INTRODUCTION}

Mobile technology has equipped with several sensors for better usability purpose such as GPS, compass, and gyroscope for tracking and orientation purposed. This feature has stimulated augmented reality application to evolve further and feasible to be used as the daily basis. This project intends to develop wayfinding guidance as a support for King Abdulaziz University to be a smart campus. The user will be able to find the location of a building with the help of attractive AR application that can be integrated into real life people experience. As we know, the mobile augmented reality application. Since the milestone of real-virtual object collaboration by Sutherland in 1965 [1], Augmented Reality (AR) has undergone a tremendous development, particularly in tracking methods. Registration and tracking methods for augmenting virtual objects in the real world have been explored by many researchers. Zhou et.al regarded tracking as one of the fundamental elements in the construction of a decent Augmented Reality

\footnotetext{
${ }^{*}$ Corresponding author
} 
system [2]. Most of the tracking techniques fall into two categories: vision-based and sensor-based tracking technique.

Sensor-based tracking techniques rely on not only camera but also specialized sensors such as ultrasonics or initials. Sensors can provide information about the environment to the system, and then augmentation can be done to the scene captured by the camera. The earlier technique incorporates ultrasonics and GPS sensor to obtain their location with respect to calibration point, such as [3] [4] [5]. Inertial sensors such as gyroscopes and accelerometers can provide direct spatial information to the system. These sensors can be mounted on the user's HMD and calculate the user's head position as the camera pose. Examples of such method can be seen in [6] [7]. Prior to recently, such sensors are very expensive and practically not portable.

In contrast, vision-based tracking deduce camera pose from scene captured by that particular camera. The potential of vision-based technique comes from the device requirements; a camera is the only device needed to obtain information required to perform the tracking. In this kind of method, the crucial problem is how can the system deduce the relationship between real-world environment and virtual objects based solely on the captured image sequences [8]. The early vision-based technique utilizes fiducial markers to aid system in computing the features by simplifying the deduction to these fiducials. The well-known library ARToolKit [9] used black square markers as a base for the tracking process. Various kinds of markers have also been proposed, such as a square with barcodes [10] [11], circular [12] and color markers [13]. Because of its simplicity, the market-based technique can deliver a fast and robust augmented reality experience. A comparative study [14] contrasts the performance of several marker-based techniques.

In spite of its performance, the use of markers limits the implementation domain of such approaches, such as in an occluded scene or a large environment like outdoors. Hence, more recent techniques focus more on developing tracking technique by exploiting natural features captured from the scene such as edges, corners, etc. and deduce the camera pose based on those, namely markerless tracking. Some techniques use pre-trained model (CAD, etc) to the system. The system will then try to search these model on the captured frame. Lee and Hollerer [15] applied to skin color histogram and contours to provide hand-recognition tracking. Pictures and photographs have been used as training model also, e.g. by utilizing chaotic neural network [16], feature transform of SIFT [17], or a bi-clustering process of visual vocabulary [4]. Previous research introduced planar detection in unknown surroundings such as wall, surface and working area without predefined information, e.g. marker or location based. If the section is unidentified, e.g. there is no previous data for tracing, it is deliberated as a very problematic assignment. Therefore, the previous study presented a limit for tracing planar sections solitary [4] [18] [19]. Several AR tracing approaches emphasis further on tracing planar, unidentified surroundings. It endeavors to presume the tracing deprived of preliminary information of the scene and placed the data in particular formula of an atlas. Normally named as SLAM, once innovative landscapes were exposed, it enlarges the atlas so the information breeds exponentially.

Neubert et.al used SLAM to construct models from the captured scene [20]. Another approach for this is by separating tracking and mapping process while providing a robust SLAM technique, which was done by PTAM [20]. The tracking thread calculates camera pose from the map, while the mapping process adds the more reliable feature to it simultaneously. PTAM managed to robustly track and augment scene of more than 4000 point features. However, SLAM technique requires a substantial amount of computational costs when too many features are being tracked on the map. In order to develop seamless interaction between real and virtual world, tracking technique used requires being not only robust but also computationally efficient. The motivation of this research comes from the requirement of highly accurate markerless tracking in an unknown environment by feature-based tracking, but without sacrificing processing speed. Direct information from sensors can be used to complement such issue. With the development of digital MEMS, inertial sensors are become affordable and can fit in small devices such as smartphones [20]. The proposed technique is a hybrid tracking which collaborates SLAM technique to develop feature map and inertial sensors to aid the motion estimation of camera movement relative to the map.Augmented reality realism involves so many aspects such as facial expression that can boost virtual human realism when they perform interaction in the virtual environment [21] [22] [23] [24] [25] [26] [27] [28]. EEG signal and haptic technology also used to express the human inner emotion to be transferred into virtual human expression [29] [30] [31]. Some researcher tracks the human body such as arm and hand [32] [33] to control the interaction with human anatomy $3 \mathrm{D}$ model. The augmented reality also received a lot of attention since touch sensation is applied to particular AR devices [34]. Markerless tracking in AR is important to move from researcher to provide dynamic imposed toward desired area or region. We don't need to apply particular marker for each object, some researcher uses Wii remote to accelerate the tracking speed [33][34] [35]. The immersion of virtual human in virtual or augmented reality also determined by the sense of touch also known as haptic technology. This approach will enable the realism of virtual human to another level [36] [37] [38] [39]. 


\section{METHODS}

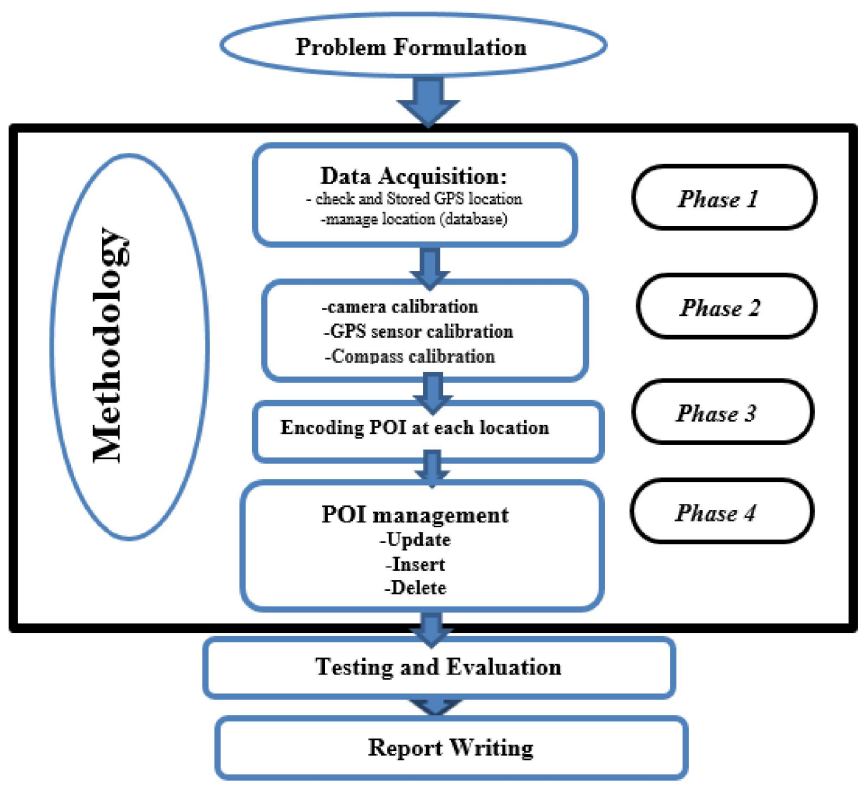

Figure 1. Project Methodology

In Figure 1, the process is started by gathering the data that include managing GPS locations after and check and stored GPS location. Then use the Camera and GPS sensor and campus calibrations to determine the location. After the location is determined to start encoding the POI at each location. Finally, management of the POI such update and insert and delete.

Material for experiments covers: IOS devices and Computer with high-end Processor and Graphics for processing. The process of calculating the distance between camera position and destination are conducted in following steps:Stored the GPS coordinate of each destination in the database, Read the Mobile Phone GPS coordinate, Read the Destination GPS coordinate from the database, GPS coordinate will be used to compute the theoretical azimuth(Figure 2 and Figure 3), Provide the actual azimuth of the mobile devices, and Render the Point of Interest(POI).

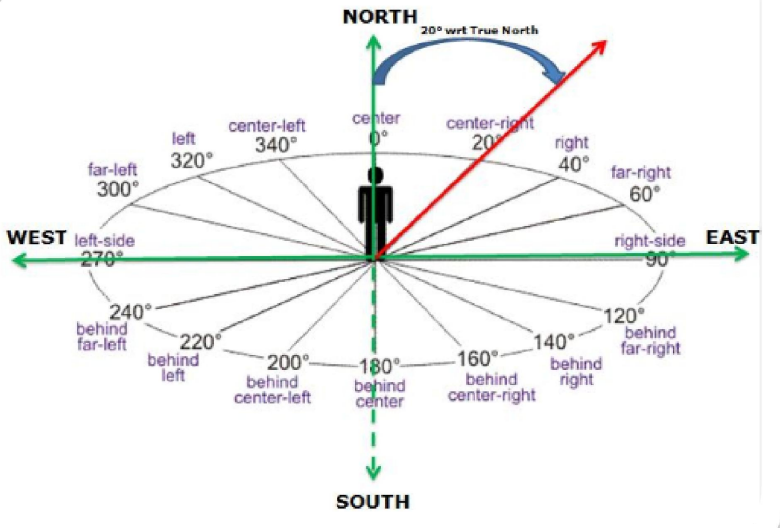

src:directionaldrilling.blogspot.com

Figure 2. Azimuth Orientation [38] 


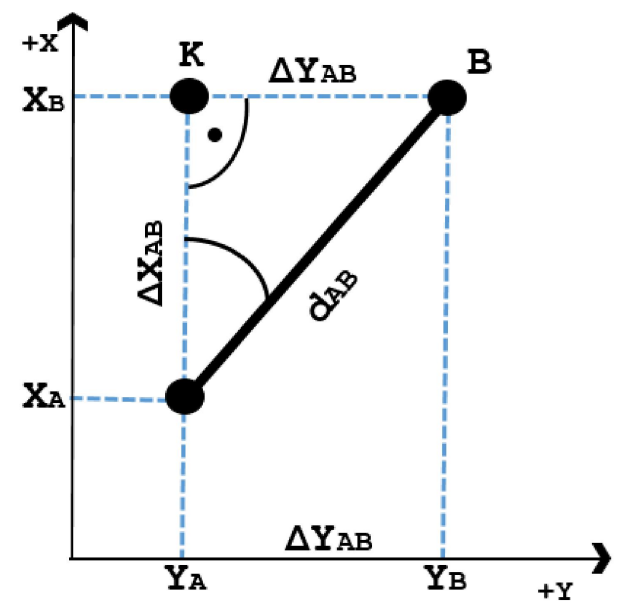

Figure 3. POI calculation based on azimuth orientation [38]

Figure 2 shows the azimuth position of human toward earth direction while Figure 3 is describing the method of calculating the angle for Point of Interest (POI) for each location.

As pointed in Figure 3, the angle on the right triangle can derive the angle $(\varphi)$. The calculation of POI angle is the difference of $\mathrm{Y}$ axis and $\mathrm{X}$ axis as a distance in the real world.

$$
\tan \varphi A B=\frac{\Delta Y_{A B}}{\Delta X_{A B}}
$$

\section{RESULTS}

The proposed application provides some features for user interaction with the system that classified as a functional and non-functional requirement; Figure 4 portrays the use case diagram of the proposed system.

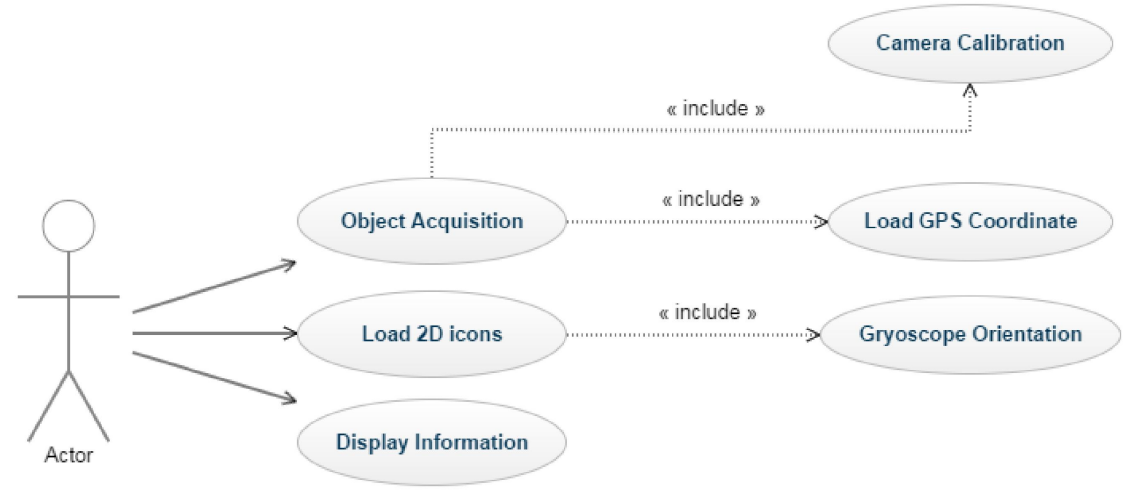

Figure 4. Use Case Diagram

Geo-location Tracking: The location of particular devices can be tracked through the sensor that provides a realworld coordinate of a thing such as sonar, radar, hand phone with GPS features and PC that connected to the network. The longitude and latitude of an object will be generated according to the world map, commonly Google Map.

Camera Orientation \& calibration: User shall identify the places by just pointing the camera to the desired location or by giving the radius of locations where he intends to go without typing anything. The menu provides a tab called Geo-Location tracking and user can access whenever it's needed. Geo-location tracking will be started and its connected to GPS system in real time. The apps will read the latitude and longitude of the current user location then it will show all POIs within the radius of the location. POIs are stored previously by admin and is used for calculating the distance between the current location and desired destination. The output data are displayed 
visually to the user by using labels. When the user taps each label, the description of the place with a photo, contact number and email of the building.

2D POI display: This displays the POIs with the data in a map. Inside the application, a map of a university and surrounded area are created and when the user enters the desired location as the input, the system checks the data and compare with closed locations. Finally, those places shall be indicated on the map.Actor Description: The actor in the Figure 4 system represents the visitor or new student the proposed apps. The following Tables 1, 2 and 3 describe the use case for user and System.

TABLE 1

Description of ObJeCt ACQUisition Use CASE

\begin{tabular}{|c|c|}
\hline Use case name & Object Acquisition \\
\hline Scenario: & Facing the camera into target \\
\hline Description: & Camera will track the position of the real object then saved the location direction \\
\hline Actors: & User \\
\hline Related Use Cases: & Include: Camera Calibration, Load GPS Coordinate. \\
\hline Preconditions: & Camera is online \\
\hline Post conditions: & Object Tracked \\
\hline Flow of Activities: & System \\
\hline & 1.Facing the camera to desired direction \\
\hline Exception Conditions: & $\begin{array}{l}\text { 2. Direction not recognized. } \\
\text { 3. GPS location not detected. }\end{array}$ \\
\hline
\end{tabular}

TABLE 2

DESCRIPTION OF LOAD 2D ICONS USE CASE.

\begin{tabular}{|c|c|}
\hline Use case name: & Load 2D icons \\
\hline Scenario: & Popup an 3D icon \\
\hline Description: & When facing the camera on target its popup an $3 \mathrm{D}$ icon with information about the target. \\
\hline Actors: & User \\
\hline Related Use Cases: & Include: Gyroscope orientation \\
\hline Preconditions: & Object Tracked \\
\hline Post conditions: & Popup an 3D icon \\
\hline Flow of Activities: & $\begin{array}{l}\text { User } \\
\text { 1. Facing the camera to desired direction }\end{array}$ \\
\hline Exception Conditions: & $\begin{array}{l}\text { 2. Pop up the 3D Icons on the desired target. } \\
\text { 1. 3D icon didn't popup. } \\
\text { 2. GPS location not detected. } \\
\text { 3. Camera not working }\end{array}$ \\
\hline
\end{tabular}

TABLE 3

DESCRIPTION OF DISPLAY INFORMATION USE CASE.

\begin{tabular}{|c|c|c|}
\hline Use case name: & \multicolumn{2}{|l|}{ Display information } \\
\hline Scenario: & \multicolumn{2}{|l|}{ Slideshow the information } \\
\hline Description: & \multicolumn{2}{|c|}{ When the $3 \mathrm{D}$ icon popup press on (i) button to get information about the target } \\
\hline Actors: & \multicolumn{2}{|l|}{ User } \\
\hline Related Use Cases: & \multicolumn{2}{|l|}{ None } \\
\hline Preconditions: & \multicolumn{2}{|l|}{ Popup an 3D icon } \\
\hline Post conditions: & \multicolumn{2}{|l|}{ Show the information } \\
\hline \multirow[t]{2}{*}{ Flow of Activities: } & User & System \\
\hline & $\begin{array}{l}\text { 1. Direct the target. } \\
\text { 2. Pop up the } 3 \mathrm{D} \text { Icons on the desired target. } \\
\text { 3. Press (i) button. } \\
\text { 4. Show information. }\end{array}$ & Information displayed Successfully. \\
\hline Exception Conditions: & $\begin{array}{l}\text { 1. The (i) button didn't work. } \\
\text { 2. Show wrong information. }\end{array}$ & \\
\hline
\end{tabular}




\section{DisCUSSION}

The project has several main goals such as real-time tracking for the building which require the user to give permission location services to get his location. The second goal is to track user orientation phone towards the direction and building. The third goal is to display the 2D icon that contains information about the name of building and distance to it.

Figure 5.A shows the location of the faculty of computing and information technology Rabigh; it has revealed that distance around 75 meters straightforward. Whilst, Figure 5B display is POI in detail that exposed the building information and link toward faculty web and Google map. Figure 5 illustrates that once the POI is clicked; the detail information is exposed and connected with faculty or university website.
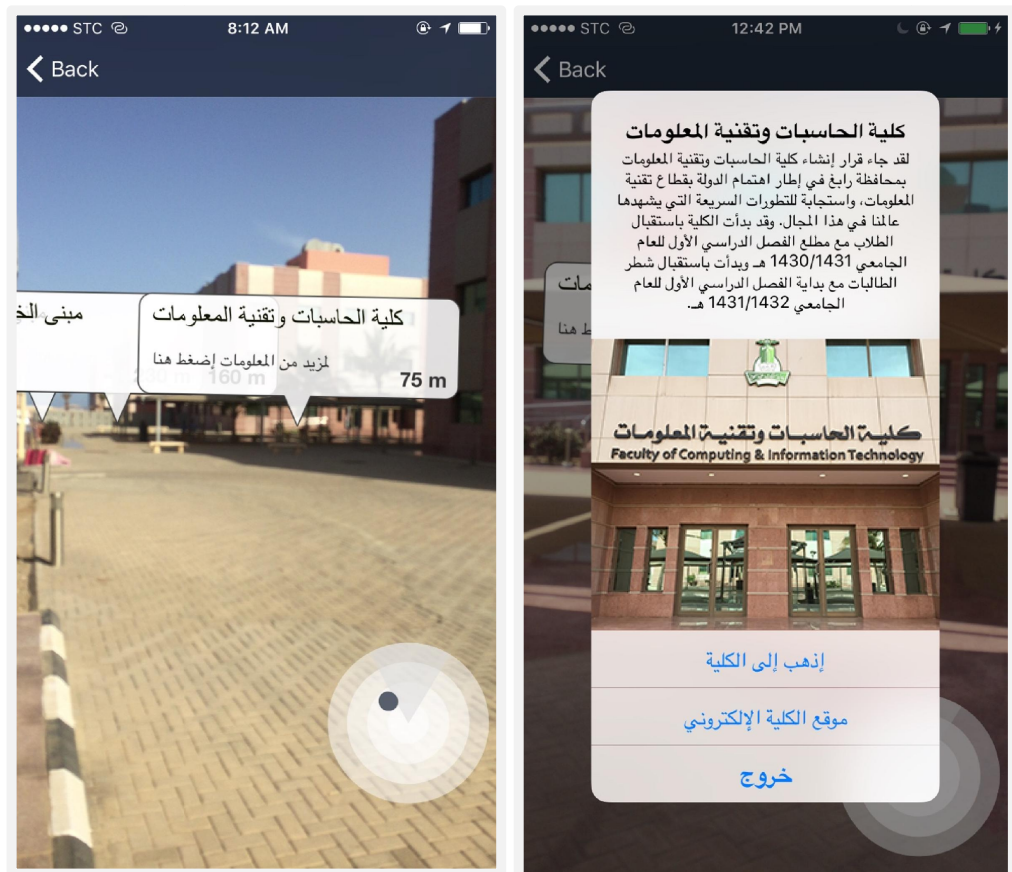

Figure 5. (A). Location of Faculty with the Distance, (B). Detail of POI Information after Clicked

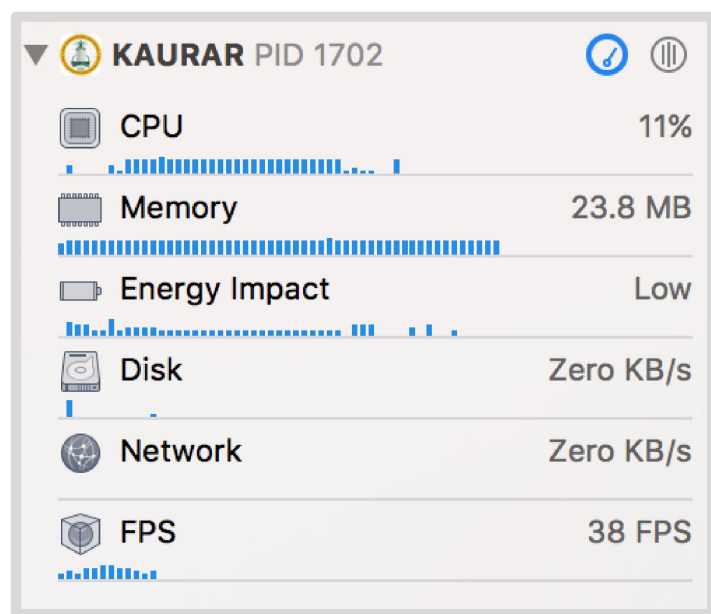

Fig. 6 Map View Performance

\begin{tabular}{|c|c|}
\hline V (2) KAURAR PID 1702 & (2) (III) \\
\hline (1) CPU & $83 \%$ \\
\hline Memory & $24.5 \mathrm{MB}$ \\
\hline$\square^{p}$ Energy Impact & High \\
\hline Disk & Zero KB/s \\
\hline (9) Network & Zero KB/s \\
\hline (9) FPS & 49 FPS \\
\hline
\end{tabular}

Fig. 7 AR Performance

The performance by loading map view will require CPU $11 \%$ and $23.8 \mathrm{Mb}$ of memory. The FPS still quite high with 38FPS, refer to Figure 6 for map view performance. When the user launches the AR apps, it will boost up the CPU usage until $83 \%$ then memory also increase a little bit. The increment in CPU because these apps utilize the GPS sensor, gyroscope, and camera device at the same time. The FPS still good with 49 value, refer to Figure 7. 


\section{CONCLUSIONS}

Intelligence context-aware mobile augmented reality is a user-friendly application that allows visitor, new student or staff getting familiar with campus location and event easily. The proposed application is provided to augment the user pleasure and easiness with self-touring familiarity with the King Abdul Aziz University and its Rabigh branch. It is proven by the snapshot (Figure 5.A and 5B) in the discussion section; the user can easily point out the desired location along with its distance and direction that appear in their mobile phone camera. They also can click the POI and find more detail information. The most typical needs of students and visitors of the university are being calculated and taken into consideration for the development of the system. There is no heavy user involvement in data or information processing only they need to get to know the correct details for the purpose of navigating through the premises of the university. Before this system was first introduced and implemented, many of the visitors had faced the common general issues that have been addressed by the application in present time. The implementation of the augmented reality campus navigation has quite impact on the university environment, given that the system allows students, lecturers, and visitors navigate in both outdoor and indoor, search for a place of interest, view availability of a person of interest with complete ease. According to feedback from users, the noncumbersome of self-touring has motivated them on using and spreading this system's usefulness to others. It's more of time and effort saving of the users of the system, which is an advantage that differentiates it from other systems.

\section{ACKNOWLEDGMENTS}

This work was supported by the Deanship of Scientific Research (DSR), King Abdulaziz University, Jeddah Saudi Arabia. The authors, therefore, gratefully acknowledge the DSR technical and financial support.

\section{REFERENCES}

[1] Sutherland, I. E. In The Ultimate Display, IFIP Congress, 1965; 1965; pp 506-508.

[2] Zhou, F.; Duh, H. B.-L.; Billinghurst, M. In Trends in Augmented Reality Tracking, Interaction and Display : A Review of Ten Years of ISMAR, 7th International Symposium on Mixed and Augmented Reality (ISMAR 2008) : ACM \& IEEE, 2008; $2008 ; \mathrm{pp} 193-202$.

[3] Azuma, R.; Bishop, G. In Improving Static and Dynamic Registration in an Optical See-through HMD, 1st Annual Conference on Computer graphics and interactive techniques (SIGGRAPH), New York, 1994; ACM: New York, 1994; pp 197-204.

[4] Foxlin, E.; Harrington, M.; Pfeifer, G. In Constellation ${ }^{\mathrm{TM}}$ : A Wide-Range Wireless Motion-Tracking System for Augmented Reality and Virtual Set Applications, SIGGRAPH' 98 Computer Graphics and interactive techniques, Orlando, Florida, 1998; ACM Orlan-do, Florida, 1998; pp 371-378.

[5] Azuma, R.; Hoff, B.; Neely III, H.; Sarfaty, R. In A Motion-Stabilized Outdoor Augmented Reality System, IEEE Virtual Reality, California, 1999; IEEE CS Press: California, 1999; pp 252-259.

[6] Welch, G.; Bishop, G.; Vicci, L.; Brumback, S.; Keller, K.; Colucci, D. n., High-Performance Wide-Area Optical Tracking : the HiBall Tracking System. Presence 2001, 10, 1-21.

[7] Sawada, K.; Okihara, M.; Nakamura, S., A Wearable Attitude-Measurement System Using a Fiberoptic Gyroscope. Presence 2002, 11, 109-118.

[8] Yuan, M. L.; Ong, S. K.; Nee, A. Y. C., A Generalized Registration Method for Augmented Reality Systems. Computers and Graphics 2005, 29, 980-997.

[9] Kato, H.; Billinghurst, M. In Marker tracking and HMD calibration for a video-based augmented reality conferencing system, 2nd IEEE and ACM International Workshop on Augmented Reality (IWAR'99), Washington DC, 1999; IEEE Comput. Soc: Washington DC, 1999; pp 85-94.

[10] Fiala, M. In ARTag, a fiducial marker system using digital techniques IEEE Computer Society Conference on Computer Vision and Pattern Recognition, 2005. CVPR 2005., 2005; 2005; pp 590-596.

[11] Rekimoto, J. In Matrix : A Realtime Object Identication and Registration Method for Augmented Reality, Asia Pacific Computer Human Interaction 1998 (APCHI'98), 1998; IEEE Comput. Soc: 1998; pp 63-68.

[12] Naimark, L.; Foxlin, E. In Circular data matrix fiducial system and robust image pro-cessing for a wearable vision-inertial self-tracker, $1 s t$ International Symposium on Mixed and Augmented Reality, 2002; 2002; pp 27-36.

[13] Cho, Y.; Neumann, U., Multiring Fiducial Systems for Scalable Fiducal-Tracking Augmented Reality. Presence 2001, $10,599-612$.

[14] Zhang, X.; Fronz, S.; Nassir, N. In Visual marker detection and decoding in AR systems: A comparative study, 1st International Symposium on Mixed and Augmented Reality (ISMAR 02), 2002; IEEE Comput. Soc: 2002; pp 97-106.

[15] Lee, T.; Hollerer, T. In Handy AR: Markerless Inspection of Augmented Reality Objects Using Fingertip Tracking, 11th IEEE International Symposium on Wearable Computers, 2007; Ieee: 2007; pp 1-8.

[16] Lowe, D. G. In Object Recognition from Local Scale-Invariant Features, International Conference of Computer Vision (ICCV), 1999; 1999; pp 1150-1157.

[17] Li, X.; Chen, D. In Augmented reality in e-commerce with markerless tracking, 2010 2nd IEEE International Conference on Information Management and Engineering, 2010; Ieee: 2010; pp 609-613. 
[18] Klein, G.; Murray, D. In Parallel Tracking and Mapping for Small AR Workspaces, 6th International Symposium on Mixed and Augmented Reality (ISMAR 2007) : IEEE \& ACM, Orlando, 2007; IEEE: Orlando, 2007; pp 225-234.

[19] Neubert, J.; Pretlove, J.; Drummond, T. In Semi-Autonomous Generation of Appearance-based Edge Models from Image Sequences, ISMAR '07 Proceedings of the 2007 6th IEEE and ACM International Symposium on Mixed and Augmented Reality, Washington DC, 2007; Washington DC, 2007; pp 1-9.

[20] Yazdi, N.; Ayazi, F.; Najafi, K., Micromachined Inertial Sensors. Proceedings of the IEEE 1998, 86, 1640-1659.

[21] F.N.Afif, Basori, A.H. and N.Saari, Vision based Tracking Technology for Augmented Reality: A Survey, International Journal of Interactive Digital Media, Vol. 1, No. 1, (2013).

[22] Afif, F.N., Basori, A.H., Almazyad, A.S. et al.,"Fast Markerless Tracking for Augmented Reality in Planar Environment", Procedia Social and Behavioral Sciences, Volume 97, 6 November 2013, Pages 648-655.

[23] Basori, A.H. and Afif, F.N.," Orientation Control for Indoor Virtual Landmarks based on Hybrid-based Markerless Augmented Reality", 3D Res (2015) 6: 41. https://doi.org/10.1007/s13319-015-0072-5.

[24] Basori, AH, Qasim AZ. Extreme expression of sweating in 3D virtual human. Computers in Human Behavior. 2014 Jan 1;35:307-314. Available from, DOI: $10.1016 /$ j.chb.2014.03.013

[25] Basori, A.H., et al., The feasibility of human haptic emotion as a feature to enhance interactivity and immersiveness on virtual reality game, in Proceedings of The 7th ACM SIGGRAPH International Conference on Virtual-Reality Continuum and Its Applications in Industry. 2008, ACM: Singapore. p. 1-2.

[26] Alkawaz, H.M, Basori, A.H., Hashim, S.Zet al., "Oxygenation absorption and light scattering driven facial animation of natural virtual human", Multimedia Tools and Applications,pp 1-37. DOI 10.1007/s11042-016-3564-2

[27] Alkawaz,H.M., Basori, A.H., Mohamad,D. and Mohamed,F. "Realistic Facial Expression of Virtual Human Based on Color, Sweat, and Tears Effects," The Scientific World Journal, vol. 2014, Article ID 367013, 9 pages, 2014. doi:10.1155/2014/367013

[28] Basori, A.H.," Emotion Walking for Humanoid Avatars Using Brain Signals", International Journal of Advanced Robotic Systems, Vol.10, http://journals.sagepub.com/doi/ abs/10.5772/54764, doi:10.5772/54764

[29] Ahmed,M.A.K, Basori, A.H. "The Influence of Beta Signal toward Emotion Classification for Facial Expression Control through EEG Sensors ", Procedia Social and Behavioral Science, Elsevier, 6 Nov 2013, DOI: 10.1016/j.sbspro.2013.10.294

[30] Basori, A.H, Bade. A, Sunar.M.S.,Daman.D, Saari.N, Hj.Salam,MD.S (2012). An integration Framework of Haptic Feedback to Improve Facial Expression, International Journal of Innovative Computing, Information and Control (IJICIC)Vol.8, No.11, November 2012

[31] Abdullasim,N, Basori, A.H., Salam,M.D, Bade,A.”Velocity Perception: Collision Handling Technique for Agent Avoidance Behavior",Telkomnika, Vol. 11, No. 4, April 2013, pp. $2264 \sim 2270$

[32] Yusoff ,M.A, Basori, A.H., Mohamed,F. "Interactive Hand and Arm Gesture Control for 2D Medical Image and 3D Volumetric Medical Visualization", Procedia Social and Behavioral Science, Vol.97, 6 November 2013, Pages 723-729, Elsevier

[33] Suroso,M.R., Basori, A,H., Mohamed,F. "Finger-based Gestural Interaction for Exploration of 3D Heart Visualization", Procedia Social and Behavioral Science, Vol.97, 6 November 2013, Pages 684-690, Elsevier

[34] Hard, J. and Alexander, J. (2012) Toolkit support for interactive projected displays. In Proceedings of the 11th International Conference on Mobile and Ubiquitous Multimedia (MUM '12). ACM, New York, NY, USA,Article 42 , 10 pages. DOI=http://dx.doi.org/10.1145/2406367.2406419.

[35] Basori, A,H. Fadhil Noer Afif, Abdulaziz S. Almazyad, Hamza Ali Abujabal, Amjad Rehman, and Mohammed Hazim Alkawaz. 2015. Fast Markerless Tracking for Augmented Reality in Planar Environment. 3D Res. 6, 4, Article 72 (December 2015),pp 1-11. DOI=http://dx.doi.org/10.1007/s13319-015-0072-5

[36] Basori, A.H., Daut Daman, Abdullah Bade, et. al. 2008. The feasibility of human haptic emotion as a feature to enhance interactivity and immersiveness on virtual reality game. In Proceedings of The 7th ACM SIGGRAPH International Conference on Virtual-Reality Continuum and Its Applications in Industry (VRCAI '08). ACM, New York, NY, USA, Article 37,2 pages. DOI=http://dx.doi.org/10.1145/1477862.1477910

[37] Basori, A.H., A Tenriawaru, ABF Mansur, Intelligent avatar on E-learning using facial expression and haptic, TELKOMNIKA (Telecommunication Computing Electronics and Control),Vol. 9 (1), 115-124, 2011

[38] Immersions Lab,”Augmented Reality”, http://blogs.immersionslabs.com/2018/02/07/augmented-reality/, Last Accessed:31 March 2018

[39] Albaqami, N.M, Allehaibi, K.H, Basori, A.H., (2018) "Augmenting Pilgrim Experience and Safety with Geo-location Way finding and Mobile Augmented Reality”, International Journal of Computer Science and Network Security, Vol.12, No.2, pp.23-32 